\title{
Role of barium enema examination for the diagnosis of submucosal invasion depth in T1 colorectal cancers
}

Keisuke Kawasaki ${ }^{1,2^{*}}$ (D, Takehiro Torisu' ${ }^{1}$, Takahisa Nagahata ${ }^{1}$, Motohiro Esaki ${ }^{3}$, Koichi Kurahara ${ }^{4}$, Makoto Eizuka ${ }^{2,5}$, Yoshihito Tanaka ${ }^{5}$, Minako Fujiwara ${ }^{6,7}$, Shinichiro Kawatoko ${ }^{1,7}$, Yumi Oshiro ${ }^{8}$, Shun Yamada ${ }^{2}$, Koji Ikegami $^{4}$, Shin Fujioka', Yuta Fuyuno ${ }^{1}$, Yuichi Matsuno', Junji Umeno' ${ }^{1}$, Tomohiko Moriyama', Takanari Kitazono', Tamotsu Sugai ${ }^{5}$ and Takayuki Matsumoto ${ }^{2}$

\begin{abstract}
Background: The indication for endoscopic resection for submucosally invasive colorectal cancer (T1-CRC) depends on the preoperative diagnosis of invasion depth. The aim of this investigation was to evaluate the association between barium enema examination (BE) profile views and depth of submucosal (SM) invasion in CRCs.

Methods: We reviewed the radiographic and endoscopic findings of 145 T1-CRCs diagnosed from 2008 to 2019. We measured the widths of horizontal and vertical rigidity under a BE profile view corresponding to CRC and compared the values with SM invasion depth. Horizontal rigidity was defined as the horizontal length and vertical rigidity as the vertical width of the barium defect corresponding to each target lesion. The most appropriate cut-off values for predicting SM invasion $\geq 1.8 \mathrm{~mm}$ were calculated by receiver operating characteristic curve analysis.
\end{abstract}

Results: Values of horizontal rigidity $(r=0.626, P<0.05)$ and vertical rigidity $(r=0.482, P<0.05)$ correlated significantly with SM invasion depth. The most appropriate cut-off values for the prediction of SM invasion depth $\geq$ $1.8 \mathrm{~mm}$ were $4.5 \mathrm{~mm}$ for horizontal rigidity, with an accuracy of $80.7 \%$; and $0.7 \mathrm{~mm}$ for vertical rigidity, with an accuracy of $77.9 \%$. The prevalence of lympho-vascular invasion was significantly different when those cut-off values were applied (43.2\% vs. $17.5 \%$ for horizontal rigidity, $P<0.005)$.

Conclusions: In T1-CRC, values of horizontal and vertical rigidities under a BE profile view were correlated with SM invasion depth. While the accuracy of the rigidities for the prediction of SM invasion depth $\geq 1.8 \mathrm{~mm}$ was not high, horizontal rigidity may be predictive of lympho-vascular invasion, thus aiding in therapeutic decision-making.

Keywords: Barium enema, Colorectal cancer, Invasion depth, Cancer, CT colonography

\footnotetext{
* Correspondence: kawasaki.keisuke.084@m.kyushu-u.ac.jp

${ }^{1}$ Department of Medicine and Clinical Science, Graduate School of Medical

Sciences, Kyushu University, 3-1-1, Maidashi, Higashi-ku, Fukuoka 812-0054,

Japan

${ }^{2}$ Division of Gastroenterology, Department of Internal Medicine, Iwate

Medical University, Yahaba 028-3695, Japan

Full list of author information is available at the end of the article
}

(c) The Author(s). 2021 Open Access This article is licensed under a Creative Commons Attribution 4.0 International License, which permits use, sharing, adaptation, distribution and reproduction in any medium or format, as long as you give appropriate credit to the original author(s) and the source, provide a link to the Creative Commons licence, and indicate if changes were made. The images or other third party material in this article are included in the article's Creative Commons licence, unless indicated otherwise in a credit line to the material. If material is not included in the article's Creative Commons licence and your intended use is not permitted by statutory regulation or exceeds the permitted use, you will need to obtain permission directly from the copyright holder. To view a copy of this licence, visit http://creativecommons.org/licenses/by/4.0/ The Creative Commons Public Domain Dedication waiver (http://creativecommons.org/publicdomain/zero/1.0/) applies to the data made available in this article, unless otherwise stated in a credit line to the data. 


\section{Background}

Endoscopic resection (ER), such as endoscopic submucosal dissection (ESD) and endoscopic mucosal resection (EMR), has become widely accepted as a treatment of choice for colorectal epithelial neoplasms [1, 2]. According to recent guidelines, ER is indicated for high-grade dysplasia or early cancer with minimal submucosal invasion [3, 4]. However, lymph node metastasis occurs at a rate of approximately $10 \%$ among patients with surgically resected submucosally invasive (T1-) colorectal cancer (CRC). Pathologic risk factors for lymph node metastasis after complete ER are submucosal (SM) invasion depth more than $1 \mathrm{~mm}$, tumor histology (poor differentiation, signet-ring cell or mucinous carcinoma), lympho-vascular invasion, and tumor budding (grade 2/3) [5-9]. According to the 2019 guidelines proposed by the Japanese Society for Cancer of the Colon and Rectum (JSCCR), additional surgery coupled with lymph node dissection has been suggested for T1-CRC with any one or more risk factor(s) after ER [3, 8]. In contrast, Nakadoi et al. [5] showed that T1-CRCs with SM invasion depth $<1.8 \mathrm{~mm}$ without any of the above-mentioned risk factors had not metastasized. More recently, Park et al. [10] showed that SM invasion depth $>2.5 \mathrm{~mm}$ was associated with a high recurrence rate.

Barium enema examination (BE), CT-colonography and colonoscopy are the main procedures used to diagnose the invasion depth of CRC. While wall rigidity under the $\mathrm{BE}$ profile view has been shown to be predictive of invasion depth in CRC, the use of BE has been declining in recent years [11-13]. Alternatively, magnifying narrow-band imaging colonoscopy (M-NBI) and magnifying chromoendoscopy (MCE) have become more widely used for the diagnosis of colorectal epithelial neoplasms, since both procedures can be applied easily to target lesions during conventional colonoscopy, and they have high accuracy for the diagnosis of deep submucosal invasion [14-20]. M-NBI enables clear visualization of the microvascular architecture and surface structure of colorectal tumors [14]. With the use of MCE, crypt openings on the surface of the tumors, referred to as the pit pattern, can be classified into various types $[15,16]$.

To date, however, few studies have compared the association between SM invasion depth and wall rigidity under BE in T1-CRC. We thus conducted a retrospective analysis to examine the association between tumor invasion depth and wall rigidity under a $\mathrm{BE}$ profile view in T1-CRCs. We also investigated the findings of M-NBI and MCE in T1-CRCs.

\section{Methods}

\section{Study population}

The current investigation was based on retrospective data collection. We reviewed the colonoscopy database coupled with histology at our institutions from 2008 to 2019 and identified all patients with a diagnosis of T1-CRC removed endoscopically or surgically. ER was performed for colorectal lesions with a pretreatment diagnosis of up to minimal submucosal invasion, while surgery was the first choice for those with deep submucosal invasion. Among those T1-CRCs, we excluded cancers that were not evaluated by BE, M-NBI and MCE. The protocol of the present study was approved by the Institutional Review Board at each of our institutions.

Consequently, we enrolled 145 lesions in 145 patients (male/female, 77/68; mean age, 69.2 \pm 9.5 years) that were treated with ER (EMR; $n=7, \mathrm{ESD} ; n=22$ ) or surgery (colectomy with LN dissection; $n=114$, transanal minimally invasive surgery without lymph node dissection; $n=2$ ). The mean size of the lesions was $20.4 \pm 14.8$ $\mathrm{mm}$. There were 39 lesions in the right side of the colon (cecum to transverse colon) and 106 lesions in the left side of the colon (descending colon to rectum). Endoscopically, 75 lesions appeared as the protruding type, and 70 lesions as the superficial type based on the Paris classification [21].

\section{$\mathrm{BE}$ and colonoscopic evaluation}

$\mathrm{BE}$ was performed with a double-contrast technique using $100 \%$ wt./vol. barium sulphate by gastroenterologists who were experts in BE. For each CRC, the enface and profile views and in-between views were taken during $\mathrm{BE}$ under substantial luminal extension. In accordance with the procedures published by Watari et al. [13] and Matsumoto et al. [22], the presence of wall rigidity under the profile view at the site of CRC was reviewed by the observers. Also, we measured the horizontal and vertical rigidities under the $\mathrm{BE}$ profile view at the site of CRC. We defined horizontal rigidity as the horizontal length and vertical rigidity as the vertical width of the barium defect corresponding to each target lesion (Fig. 1). For lesions without rigidity, the value was measured as $0 \mathrm{~mm}$.

For the evaluation of findings obtained by $\mathrm{M}-\mathrm{NBI}$ and MCE, the Japan NBI Expert Team (JNET) classification and the pit pattern classification were applied. The JNET classification consists of four types according to superficial vessel and surface patterns (1, 2A, 2B and 3), while the pit pattern under MCE was classified into eight types

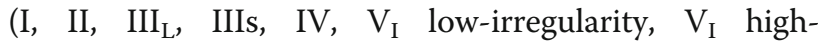
irregularity and $V_{N}$ ) [14-16]. It has been shown that type 3 of the JNET classification and the pit patterns of $V_{I}$ high-irregularity and $V_{N}$ are signs of invasion depth $\geq$ $1 \mathrm{~mm}$.

Each of the BE, M-NBI and MCE images was evaluated by two observers. Both observers were experts with experience in gastroenterological radiology and endoscopy for 16 years and nine years, respectively. They were blinded to the histopathologic findings, and they separately assessed the radiologic and endoscopic images of 


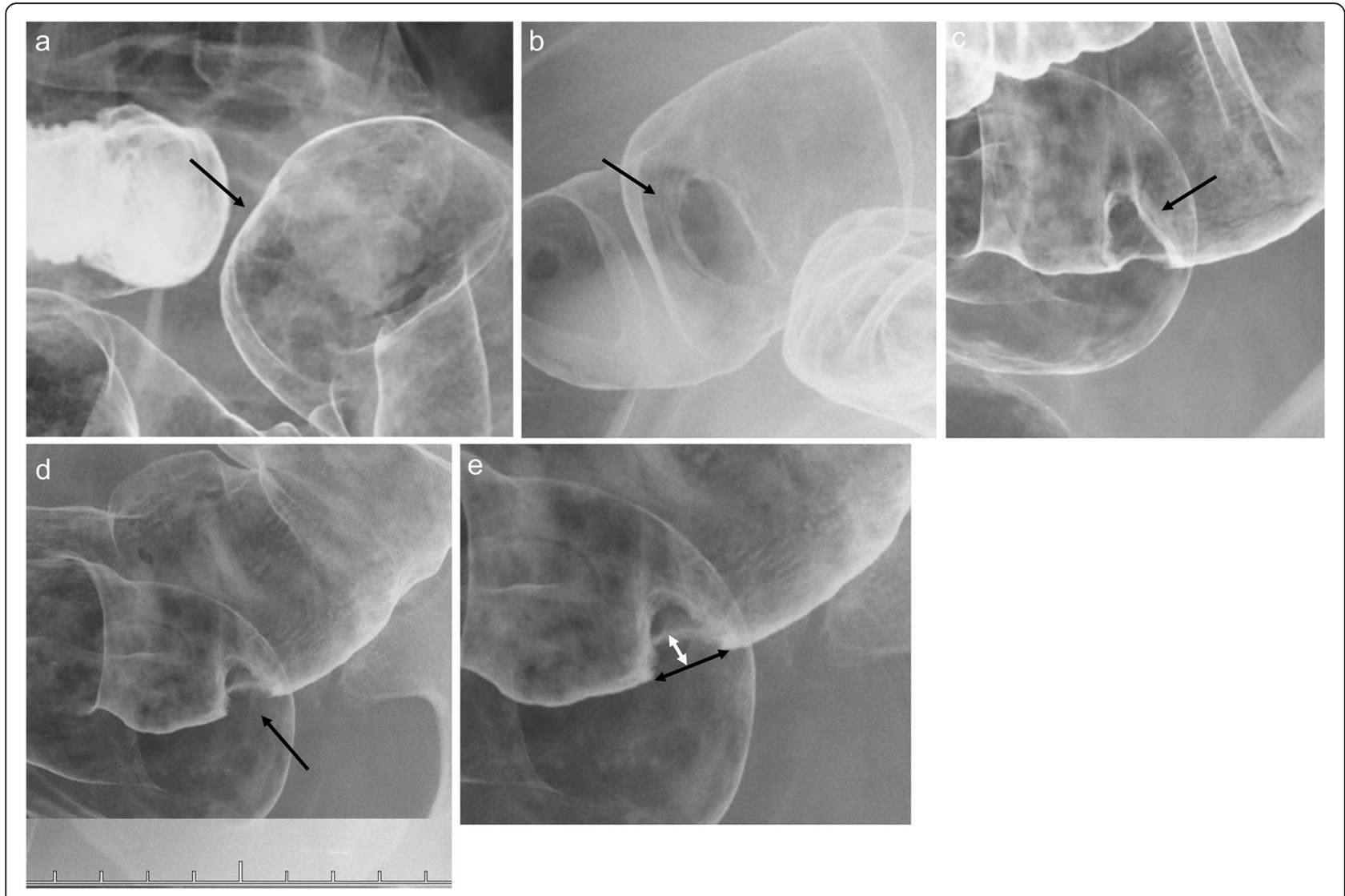

Fig. 1 Images of barium enema examination. a: Wall rigidity under the profile view at the lesion in the sigmoid colon is absent (arrow). Values of horizontal and vertical rigidities are $0 \mathrm{~mm}$. b: The enface view. There is a lesion of the protruding type in the sigmoid colon (arrow). c: The oblique view. The lesion in Fig. $1 \mathrm{~b}$ is gradually moved (arrow). d: The profile view. Wall rigidity under the profile view at the lesion in Fig. 1b is present (arrow). e: High-power view of Fig. 1d. The horizontal rigidity is $13.3 \mathrm{~mm}$ (black arrow), and the vertical rigidity is $4.4 \mathrm{~mm}$ (white arrow)

each lesion. In cases in which interpretations of BE findings of the presence of wall rigidity under the profile view or endoscopic findings were discordant, the two gastroenterologists discussed the images until a common consensus was obtained. When CRCs had wall rigidity under the BE profile view, the observers immediately measured the horizontal length and the vertical width of the barium defect at the site of CRC. The former was regarded as the horizontal rigidity and the latter as the vertical rigidity.

\section{Histopathologic evaluation}

Three pathologists, who are experts in gastrointestinal histopathology, diagnosed T1-CRCs independently according to the classification reported by the World Health Organization in 2019 [23]. The analyzed pathological items included histologic type, depth of SM invasion, lympho-vascular invasion, tumor budding, and lymph node metastasis. The depth of SM invasion was measured according to the JSCCR guidelines [3]. When it was possible to clearly identify the muscularis mucosa or to outline provisional lines for the muscularis mucosa, the depth of SM invasion was measured from the lower border of the muscularis mucosa. In cases of obscure lines for the muscularis mucosa, the depth of SM invasion was measured from the surface of the lesion. CRCs were further classified as those with invasion depth $\geq 1.8$ $\mathrm{mm}$ and those with invasion depth $<1.8 \mathrm{~mm}$ in accordance with the cut-off value reported by Nakadoi et al. [5]. The cut-off value has been shown to be predictive of lymph node metastasis in T1-CRCs. Tumor budding was defined as a single cancer cell or cancer clusters with $<5$ cancer cells observed in the invasive frontal region, and was classified as follows: grade $1,<5$ budding foci; grade 2,5 to 9 budding foci; or grade $3, \geq 10$ budding foci [9, $24,25]$.

\section{Statistical analysis}

Parametric data are expressed as mean \pm standard deviation (SD). Nonparametric data are expressed as numbers and percentages. Comparisons between any two groups were performed with the Mann-Whitney test or chi-square test where appropriate. Associations between SM invasion depth and horizontal rigidity or 
vertical rigidity were evaluated with Spearman's rank sum test ( $r$ ). For strength of association, an $\mathrm{r}$ of 0 0.10 was regarded as none, $0.10-0.39$ as weak, $0.40-$ 0.69 as moderate, $0.70-0.89$ as strong, and $0.9-1$ as very strong [26]. A receiver-operating characteristic (ROC) curve was drawn to estimate the area under the curve (AUC) and the most appropriate cut-off values for wall rigidity under the $\mathrm{BE}$ profile view to predict CRC with $\mathrm{SM}$ invasion depth $\geq 1.8 \mathrm{~mm}$. According to the most appropriate cut-off values, test values including sensitivity, specificity, positive predictive value (PPV), negative predictive value (NPV), and accuracy were calculated. The McNemar test was used to evaluate inter-examination differences in the diagnosis of invasion depth of CRC with a cut-off value of $1.8 \mathrm{~mm}$. Interobserver agreement based on kappa statistics was defined as follows: poor, $0-0.2$; fair, 0.21-0.4; moderate, 0.41-0.6; substantial, 0.610.8 ; and excellent, $0.81-1$. In each analysis, probabilities less than 0.05 were considered significant. For multiple comparison, Bonferroni correction was used. All statistical computations were performed with JMP version 13 (Statistical Discovery Program, Cary, NC, USA).

\section{Results}

Inter-observer variation in determination of radiographic or endoscopic findings

The interobserver agreement for the diagnosis of the presence of wall rigidity under the $\mathrm{BE}$ profile view was excellent $(\kappa=0.82)$, and that for the diagnosis of SM invasion depth $\geq 1 \mathrm{~mm}$ was substantial for M-NBI ( $\kappa=$ $0.69)$ and excellent for MCE $(\kappa=0.89)$.

\section{Association between clinicopathologic characteristics and wall rigidity in T1-CRC}

The mean depth of SM invasion was $2.6 \pm 1.9 \mathrm{~mm}$ (range: $0.1-12 \mathrm{~mm}$ ). Fifty-three lesions had an invasion depth of less than $1.8 \mathrm{~mm}$, while 92 lesions had a depth of $1.8 \mathrm{~mm}$ or more. Depth of SM invasion was greater for CRCs of the protruding type than the superficial type $(3.3 \pm 2.1 \mathrm{~mm}$ vs. $1.8 \pm 1.4 \mathrm{~mm}$, respectively; $P=0.0001)$, greater for CRCs with a microsurface of JNET type 3 than type $1 / 2 \mathrm{~A} / 2 \mathrm{~B}(3.2 \pm 1.8 \mathrm{~mm}$ vs. $2.2 \pm 2.0 \mathrm{~mm}$, respectively; $P=0.0001$ ), and greater for CRCs of type $V_{I}$ high-irregularity $/ \mathrm{V}_{\mathrm{N}}$ than type $\mathrm{I} / \mathrm{II} / \mathrm{III}_{\mathrm{L}} / \mathrm{IIIs} / \mathrm{IV} / \mathrm{V}_{\mathrm{I}}$ lowirregularity $(2.9 \pm 1.7 \mathrm{~mm}$ vs. $1.6 \pm 2.4 \mathrm{~mm}$, respectively; $P=0.0001)$.

Table 1 Association between clinicopathological characteristics and values of wall rigidity under the barium enema examination profile view in patients with colorectal cancers $(n=145)$

\begin{tabular}{|c|c|c|c|c|c|c|}
\hline & & Cases, $\mathrm{n}$ & Horizontal rigidity, $\mathrm{mm}$ & $P$ value & Vertical rigidity, $\mathrm{mm}$ & $P$ value \\
\hline \multirow[t]{2}{*}{ Tumor size } & $<20 \mathrm{~mm}$ & 91 & $6.0 \pm 4.3$ & 0.08 & $2.1 \pm 2.2$ & 0.12 \\
\hline & $\geq 20 \mathrm{~mm}$ & 54 & $9.1 \pm 8.3$ & & $3.3 \pm 3.7$ & \\
\hline \multirow[t]{2}{*}{ Location } & Right side of the colon & 38 & $6.2 \pm 4.9$ & 0.42 & $2.6 \pm 2.4$ & 0.36 \\
\hline & Left side of the colon & 107 & $7.5 \pm 6.6$ & & $2.5 \pm 3.1$ & \\
\hline \multirow[t]{2}{*}{ Morphology } & Protruding type & 75 & $8.5 \pm 6.2$ & 0.002 & $3.2 \pm 3.4$ & 0.006 \\
\hline & Superficial type & 70 & $5.7 \pm 5.9$ & & $1.8 \pm 2.1$ & \\
\hline \multirow[t]{2}{*}{ JNET classification } & $1 / 2 \mathrm{~A} / 2 \mathrm{~B}$ & 82 & $5.8 \pm 6.0$ & 0.0004 & $2.3 \pm 3.1$ & 0.03 \\
\hline & 3 & 63 & $8.9 \pm 6.1$ & & $2.8 \pm 2.6$ & \\
\hline \multirow[t]{2}{*}{ Pit pattern classification } & I/II/III//IIs/IVNI low-irregularity & 29 & $5.2 \pm 6.4$ & 0.02 & $2.0 \pm 3.3$ & 0.02 \\
\hline & VI high-irregularity $/ N N$ & 116 & $7.7 \pm 6.1$ & & $2.7 \pm 2.8$ & \\
\hline \multirow[t]{2}{*}{ Histologic type } & Well/mod/pap & 143 & $7.1 \pm 6.3$ & 0.31 & $2.5 \pm 2.9$ & 0.71 \\
\hline & Por/sig/muc & 2 & $9.4 \pm 1.3$ & & $2.1 \pm 0.8$ & \\
\hline \multirow[t]{2}{*}{ Depth of submucosal invasion } & $<1.8 \mathrm{~mm}$ & 53 & $3.2 \pm 4.0$ & 0.0001 & $1.2 \pm 1.7$ & 0.0001 \\
\hline & $\geq 1.8 \mathrm{~mm}$ & 92 & $9.4 \pm 6.2$ & & $3.3 \pm 3.2$ & \\
\hline \multirow[t]{2}{*}{ Lympho-vascular invasion } & Positive & 48 & $9.7 \pm 6.8$ & 0.0005 & $3.6 \pm 3.8$ & 0.008 \\
\hline & Negative & 97 & $5.9 \pm 5.6$ & & $2.0 \pm 2.2$ & \\
\hline \multirow[t]{2}{*}{ Tumor budding } & Grade 1 & 131 & $6.9 \pm 5.9$ & 0.25 & $2.5 \pm 3.0$ & 0.20 \\
\hline & Grade 2/3 & 14 & $10.1 \pm 8.6$ & & $2.9 \pm 2.2$ & \\
\hline Lymph node metastasis & Positive & 11 & $8.2 \pm 7.0$ & 0.76 & $3.0 \pm 2.6$ & 0.64 \\
\hline (Only lesions removed surgically) & Negative & 103 & $8.4 \pm 6.3$ & & $2.9 \pm 3.1$ & \\
\hline
\end{tabular}

Continuous values are indicated as mean \pm SD (standard deviation). JNET: Japan narrow-band imaging expert team well well differentiated adenocarcinoma, mod moderately differentiated adenocarcinoma, pap papillary adenocarcinoma, poor poorly differentiated adenocarcinoma, sig signet-ring cell carcinoma, muc mucinous adenocarcinoma 

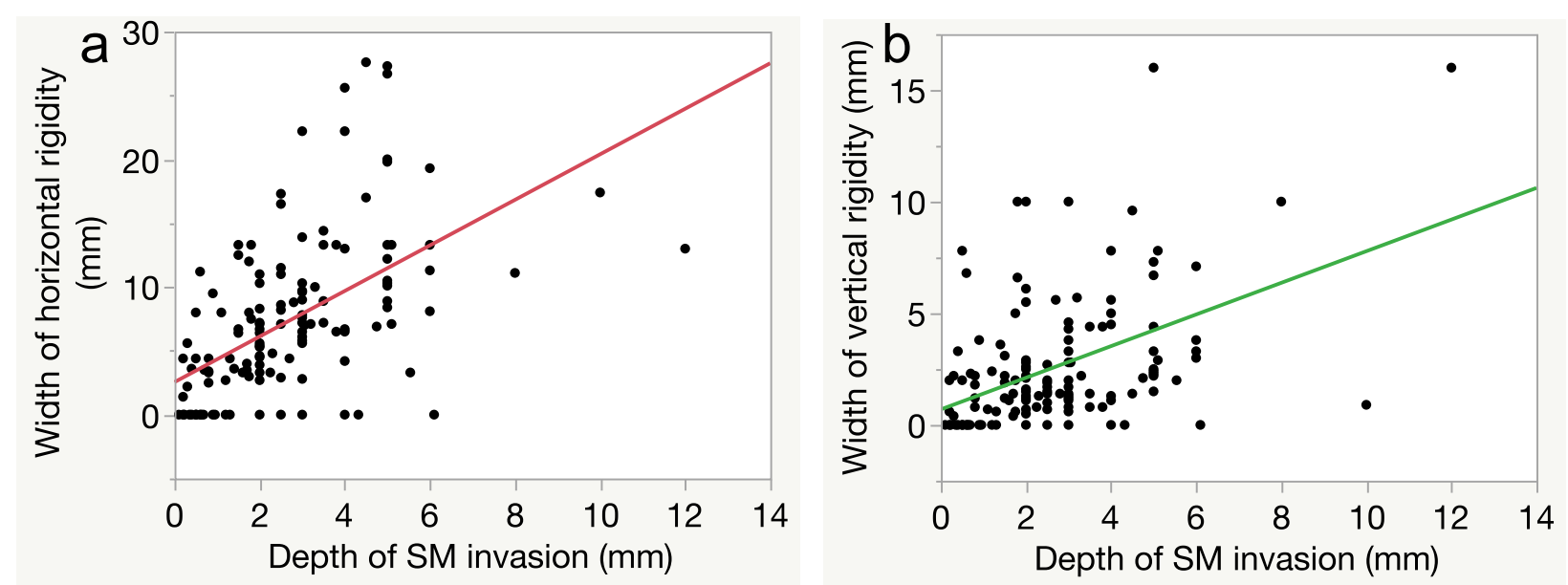

Fig. 2 Correlation between values of wall rigidity under the barium enema examination profile view and depth of submucosal (SM) invasion. a: Correlation between horizontal rigidity and depth of SM invasion. The value of horizontal rigidity is moderately correlated with depth of SM invasion $(y=1.78 x+2.55, r=0.626, P=0.0001)$. $\mathbf{b}$ : Correlation between vertical rigidity and depth of SM invasion. The width of vertical rigidity is moderately correlated with depth of SM invasion $(y=0.71 x+0.69, r=0.482, P=0.0001)$

Thirty CRCs did not have horizontal or vertical rigidity under the BE profile view. The mean value of horizontal rigidity was $7.2 \pm 6.2 \mathrm{~mm}$ (range: $0-27.6 \mathrm{~mm}$ ) while that of vertical rigidity was $2.5 \pm 2.9 \mathrm{~mm}$ (range: $0-16 \mathrm{~mm}$ ). As shown in Table 1, horizontal rigidity was significantly larger in the protruding type, type 3 of the JNET classification, and lesions with lympho-vascular invasion than in the superficial type, type $1 / 2 \mathrm{~A} / 2 \mathrm{~B}$ of the JNET classification, and lesions without lympho-vascular invasion $(P<0.005)$. Horizontal and vertical rigidities were significantly different when CRCs were classified by depth of $\mathrm{SM}$ invasion $(P=0.0001)$. The rigidities were no different when CRCs were classified by the other clinicopathologic characteristics.
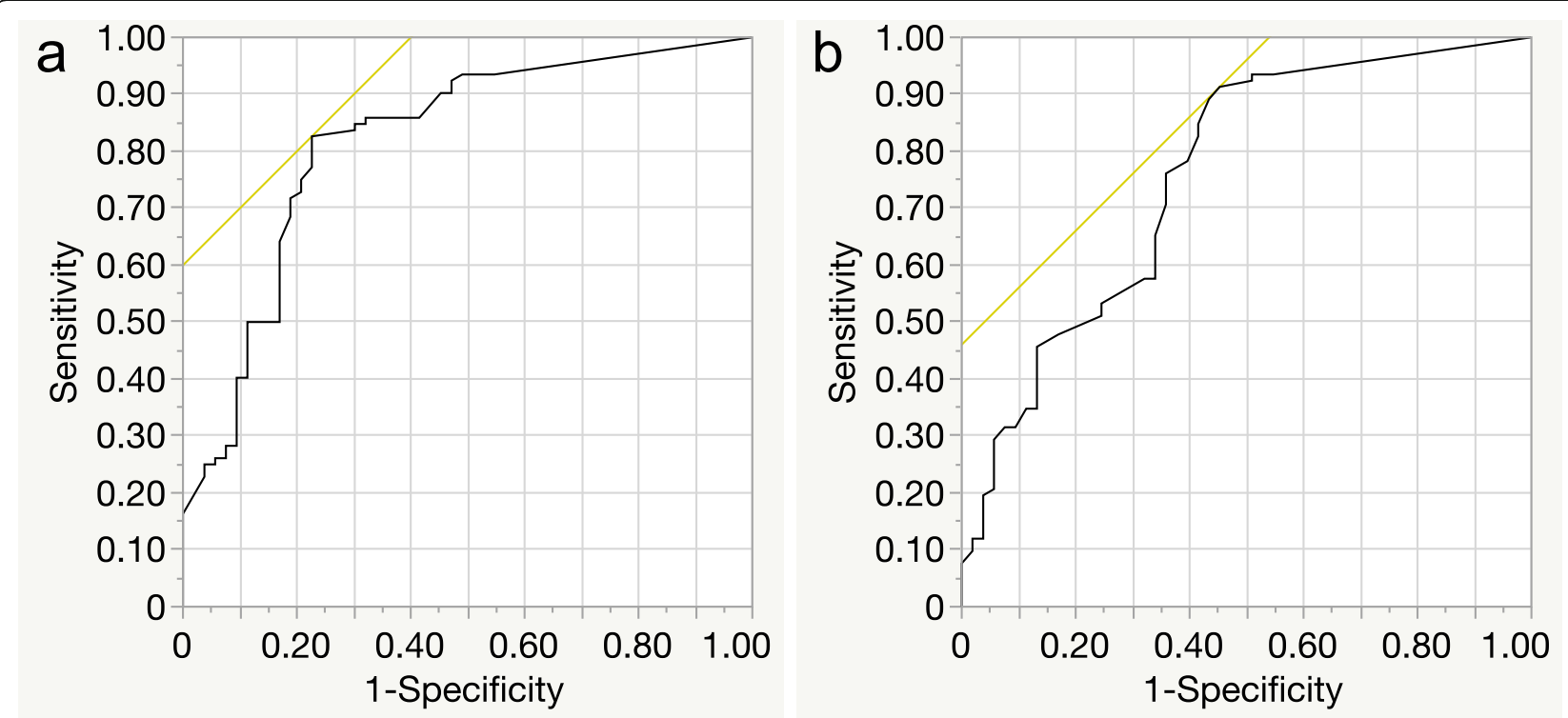

Fig. 3 Receiver-operating characteristics curves of wall rigidity under the profile view of barium enema examination for predicting submucosal (SM) invasion depth $\geq 1.8 \mathrm{~mm}$. a: The most appropriate cut-off value for horizontal rigidity was $4.5 \mathrm{~mm}$ (AUC: 0.817 ), with a sensitivity of $82.6 \%$, and a specificity of $77.4 \%$. b: The most appropriate cut-off value for vertical rigidity was $0.7 \mathrm{~mm}$ (AUC: 0.756 ), with a sensitivity of $91.3 \%$, and a specificity of $54.7 \%$ 


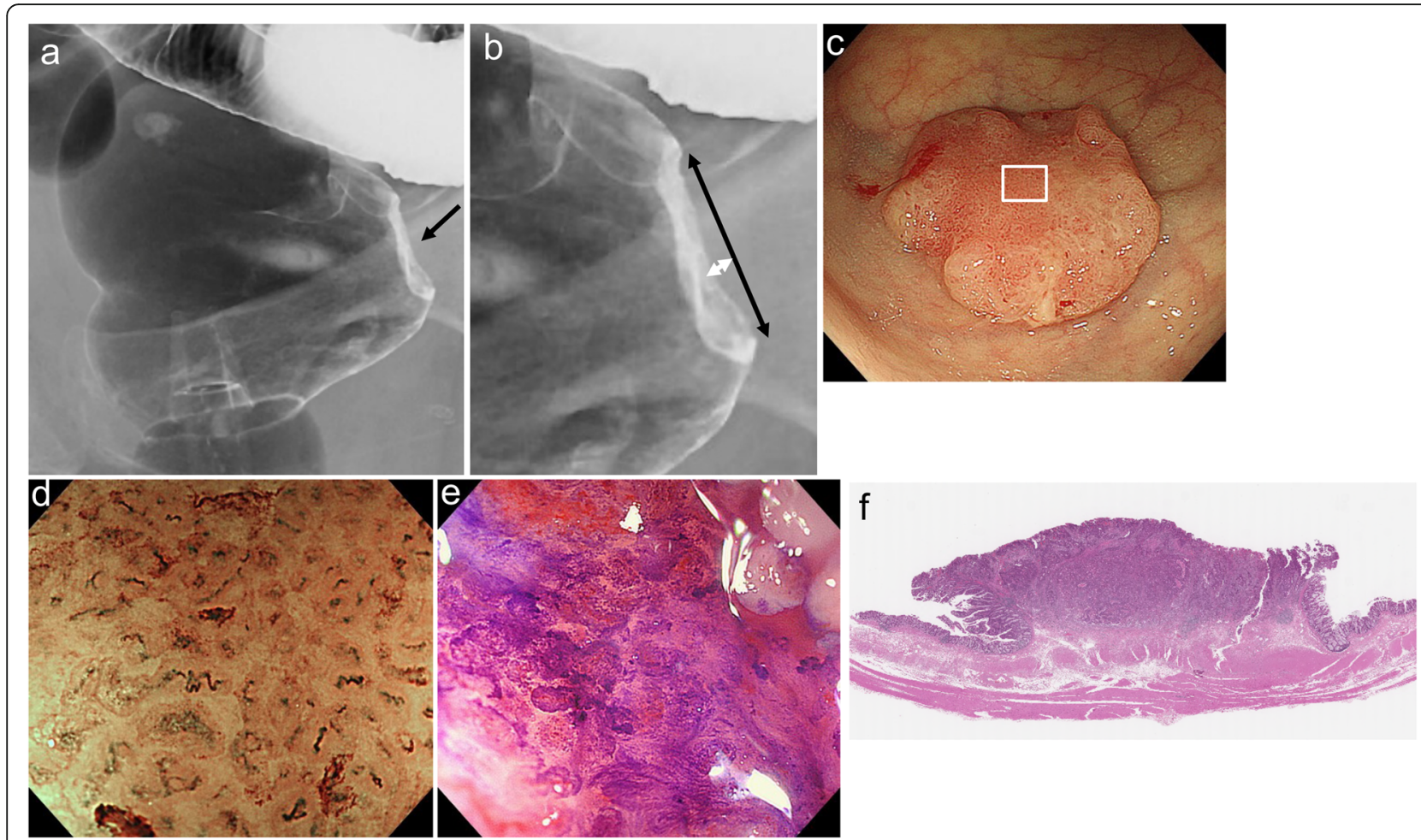

Fig. 4 Radiographic, endoscopic and histologic features of a protruding lesion in the rectum. a: Barium enema (BE) examination shows a protruding lesion with an irregular depression. Wall rigidity under the BE profile view is present (arrow). b: High-power view of Fig. 4a. Horizontal rigidity is $17 \mathrm{~mm}$ (black arrow) and vertical rigidity is $1.4 \mathrm{~mm}$ (white arrow). c: Conventional colonoscopy shows a protruding lesion with a depression. d: Magnifying narrow-band imaging (NBI) colonoscopy for the area indicated in the box in Fig. 4c reveals loss of regular surface structure and irregular vessels. These findings are compatible with type 3 of the Japan NBI expert team classification. e: Magnifying chromoendoscopy with crystal violet solutions for the same area reveals an irregular and sparse surface structure, regarded as type $V_{N}$ of the pit pattern classification. f: Histologic examination of the resected specimen shows a moderately differentiated adenocarcinoma invading the deep submucosal layer (invasion depth; $4.5 \mathrm{~mm}$ ), lympho-vascular invasion-positive, budding grade 1, lymph metastasis-negative

\section{Diagnostic value of wall rigidity for the prediction of invasion depth}

Horizontal rigidity $(\mathrm{y}=1.78 \mathrm{x}+2.55, \quad r=0.626, \quad P=$ $0.0001)$ and vertical rigidity $(\mathrm{y}=0.71 \mathrm{x}+0.69, r=0.482$, $P=0.0001$ ) showed modest correlations with the depth of SM invasion (Fig. 2). For predicting SM invasion depth $\geq 1.8 \mathrm{~mm}$, the most appropriate cut-off value was $4.5 \mathrm{~mm}$ (AUC: 0.817 ), with a sensitivity of $82.6 \%$ and a specificity of $77.4 \%$ for horizontal rigidity, and it was 0.7 mm (AUC: 0.756 ), with a sensitivity of $91.3 \%$ and a specificity of $54.7 \%$ for vertical rigidity (Fig. 3 ).

\section{Diagnostic value of wall rigidity for the prediction of clinicopathologic characteristics}

Based on the results described above, we applied cut-off values of $4.5 \mathrm{~mm}$ for horizontal rigidity and $0.7 \mathrm{~mm}$ for vertical rigidity to determine the indication for ER in CRC. When horizontal rigidity $\geq 4.5 \mathrm{~mm}$ and vertical rigidity $\geq 0.7 \mathrm{~mm}$ were defined as being positive for rigidity, 88 CRCs were positive for horizontal rigidity and 108 CRCs were positive for vertical rigidity (Fig. 4).
Further, 87 CRCs were positive for both rigidities, 22 CRCs were positive for either rigidity, and 36 CRCs were negative for both rigidities (Fig. 5).

When T1-CRCs were classified by horizontal and vertical rigidities, there were significant differences in morphology, JNET classification, and lympho-vascular invasion between lesions with positive horizontal rigidity and those without $(P<0.005)$ (Table 2$)$. There were significant differences in depth of SM invasion when lesions were classified by horizontal rigidity or vertical rigidity $(P=0.0001)$. There were no differences in the other clinicopathological characteristics between lesions classified by horizontal or vertical rigidity.

\section{Diagnostic ability of horizontal and vertical rigidities} under $B E$ for the diagnosis of $S M$ invasion depth $\geq 1.8 \mathrm{~mm}$ As shown in Table 3, the diagnostic test results of the cut-off values of $4.5 \mathrm{~mm}$ for horizontal rigidity and 0.7 $\mathrm{mm}$ for vertical rigidity were statistically significantly different $(P=0.01)$. 


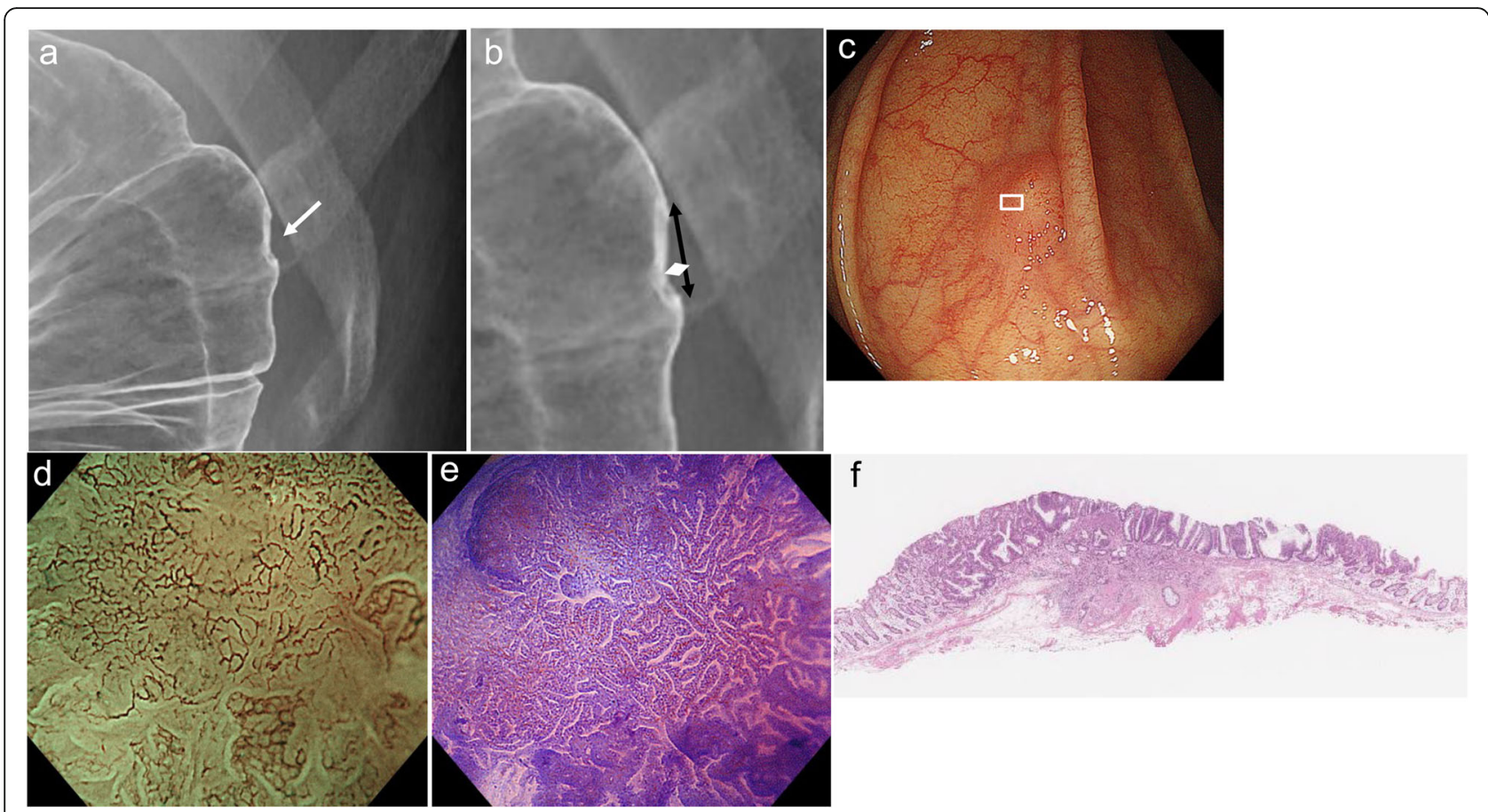

Fig. 5 Radiographic, endoscopic and histologic features of a protruding lesion in the ascending colon. a: Barium enema (BE) examination shows a protruding lesion with an irregular depression. Wall rigidity under the BE profile view is present (arrow). b: High-power view of Fig. 5a. Horizontal rigidity is $4 \mathrm{~mm}$ (black arrow) and vertical rigidity is $0.4 \mathrm{~mm}$ (white arrow). c: Conventional colonoscopy shows a protruding lesion with a depression. d: Magnifying narrow-band imaging (NBI) colonoscopy for the area indicated in the box in Fig. 5c reveals an irregular surface structure and vessels. These findings are compatible with type 2B of the Japan NBI expert team classification. e: Magnifying chromoendoscopy with crystal violet solutions for the same area reveals an irregular surface structure, regarded as type $V_{1}$ high-irregularity of the pit pattern classification. f: Histologic examination of the resected specimen shows a well-differentiated adenocarcinoma invading the deep submucosal layer (invasion depth; $1.7 \mathrm{~mm}$ ), lympho-vascular invasion-negative, budding grade 1, lymph metastasis-negative

When T1-CRCs were classified into three groups according to rigidity, SM invasion depth $\geq 1.8 \mathrm{~mm}$ was most common in lesions positive for both rigidities (86.2\%), followed by lesions positive for any one rigidity (45.5\%) and those negative for both rigidities (19.4\%) $(P=0.0001)$ (Table 4). The incidence of SM invasion $\geq 1.8 \mathrm{~mm}$ was significantly higher in lesions positive for both rigidities than in those positive for either one rigidity $(P=0.0006)$ and in those negative for both rigidities $(P=0.0003)$.

As shown in Table 5, the specificity, PPV and accuracy of horizontal rigidity and the combination of the rigidities for the diagnosis of SM invasion depth $\geq 1.8 \mathrm{~mm}$ were higher than those of vertical rigidity. In contrast, the sensitivity and NPV of vertical rigidity were higher than those of horizontal rigidity and the combination of the rigidities.

\section{Discussion}

In the present study, the values of horizontal and vertical rigidity under the $\mathrm{BE}$ profile view were correlated with the depth of SM invasion, and the horizontal rigidity was greater in lympho-vascular invasion-positive lesions than in -negative lesions. Using the most appropriate cut-off values of wall rigidity for predicting SM invasion depth $\geq 1.8 \mathrm{~mm}$, we showed that the horizontal rigidity was predictive of lympho-vascular invasion and that the two rigidities were independent of each other for the diagnosis of invasion depth in CRCs. These observations suggest that rigidity under the $\mathrm{BE}$ profile view may be useful for making therapeutic decisions in T1-CRC.

In the 2019 JSCCR guidelines, surgical resection is recommended for clinical T1b (SM invasion depth $\geq 1 \mathrm{~mm}$ ), because the rate of lymph node metastasis for CRCs with an SM invasion $\geq 1 \mathrm{~mm}$ was higher (12.5\%) than that for CRCs with an SM invasion $<1 \mathrm{~mm}(1.6 \%)$ [3, 27]. It has been reported that fold convergency, smooth surface, irregularity in depression, deep depression, and wall rigidity on the profile view are suggestive of SM invasion depth $\geq 1 \mathrm{~mm}[13,22]$. Among these $B E$ findings, wall rigidity on the profile view is a specific finding that cannot be depicted by endoscopy. Wall rigidity under the $\mathrm{BE}$ profile view has been shown to be a consequence of poor colorectal distension due to fibrosis associated with submucosal or deeper infiltration of carcinoma cells [13, 28, 29]. To date, however, no study has shown a 
Table 2 Comparison of clinicopathological characteristics in widths of wall rigidity-positive lesions and -negative lesions under profile view of barium enema

\begin{tabular}{|c|c|c|c|c|c|c|c|}
\hline & & $\begin{array}{l}\text { Horizontal } \\
\text { rigidity-positive } \\
\text { (88 lesions) }\end{array}$ & $\begin{array}{l}\text { Horizontal rigidity- } \\
\text { negative } \\
\text { (57 lesions) }\end{array}$ & $\begin{array}{l}P \text { - } \\
\text { value }\end{array}$ & $\begin{array}{l}\text { Vertical rigidity } \\
\text {-positive } \\
\text { (108 lesions) }\end{array}$ & $\begin{array}{l}\text { Vertical rigidity } \\
\text {-negative } \\
\text { (37 lesions) }\end{array}$ & $\begin{array}{l}P \text { - } \\
\text { value }\end{array}$ \\
\hline \multirow[t]{2}{*}{ Tumor size, n (\%) } & $<20 \mathrm{~mm}$ & $55(62.5)$ & $36(63.2)$ & 1.0 & $68(63)$ & $23(62.2)$ & 1.0 \\
\hline & $\geq 20 \mathrm{~mm}$ & $33(37.5)$ & $21(36.8)$ & & $40(37)$ & $14(37.8)$ & \\
\hline \multirow[t]{2}{*}{ Location, n (\%) } & $\begin{array}{l}\text { Right side of the } \\
\text { colon }\end{array}$ & $22(25)$ & $16(28.1)$ & 0.70 & $30(27.5)$ & $8(21.6)$ & 0.52 \\
\hline & $\begin{array}{l}\text { Left side of the } \\
\text { colon }\end{array}$ & $66(75)$ & $41(71.9)$ & & $78(72.2)$ & $29(78.4)$ & \\
\hline \multirow[t]{2}{*}{ Morphology, n (\%) } & Protruding type & $55(62.5)$ & $20(35.1)$ & 0.002 & $60(55.6)$ & $15(40.5)$ & 0.13 \\
\hline & Superficial type & $33(37.5)$ & $37(64.9)$ & & $48(44.4)$ & $22(59.5)$ & \\
\hline \multirow[t]{2}{*}{ JNET classification, n (\%) } & $1 / 2 \mathrm{~A} / 2 \mathrm{~B}$ & $39(44.3)$ & $43(75.4)$ & 0.0003 & $54(50)$ & $28(75.7)$ & 0.007 \\
\hline & 3 & $49(55.7)$ & $14(24.6)$ & & $54(50)$ & $9(24.3)$ & \\
\hline \multirow[t]{2}{*}{$\begin{array}{l}\text { Pit pattern classification, } \\
\text { n (\%) }\end{array}$} & $\begin{array}{l}\text { I/II/III//IIIS/IV/NI low- } \\
\text { irregularity }\end{array}$ & $11(12.5)$ & $18(31.6)$ & 0.01 & $17(15.7)$ & $12(32.4)$ & 0.03 \\
\hline & $\begin{array}{l}\text { VI high-irregularity/ } \\
\text { VN }\end{array}$ & 77 (87.5) & $39(68.4)$ & & $91(84.3)$ & $25(67.6)$ & \\
\hline \multirow[t]{2}{*}{ Histologic type, n (\%) } & Well/mod/pap & $86(97.7)$ & $57(100)$ & 0.52 & $106(98.2)$ & $37(100)$ & 1.0 \\
\hline & Por/sig/muc & $2(2.3)$ & $0(0)$ & & $2(1.8)$ & $0(0)$ & \\
\hline \multirow{2}{*}{$\begin{array}{l}\text { Depth of submucosal } \\
\text { invasion, } \mathrm{n}(\%)\end{array}$} & $<1.8 \mathrm{~mm}$ & $12(13.6)$ & $41(71.9)$ & 0.0001 & $24(22.2)$ & $29(78.4)$ & 0.0001 \\
\hline & $\geq 1.8 \mathrm{~mm}$ & 76 (86.4) & $16(28.1)$ & & $84(77.8)$ & $8(21.6)$ & \\
\hline \multirow{2}{*}{$\begin{array}{l}\text { Lympho-vascular } \\
\text { invasion, } \mathrm{n}(\%)\end{array}$} & Positive & $38(43.2)$ & $10(17.5)$ & 0.002 & $41(38)$ & $7(18.9)$ & 0.03 \\
\hline & Negative & $50(56.8)$ & $47(82.5)$ & & $67(62)$ & $30(81.1)$ & \\
\hline \multirow[t]{2}{*}{ Tumor budding, n (\%) } & Grade 1 & 78 (88.6) & $53(93)$ & 0.57 & $96(88.9)$ & 35 (94.6) & 0.52 \\
\hline & Grade $2 / 3$ & $10(11.4)$ & $4(7)$ & & $12(11.1)$ & $2(5.4)$ & \\
\hline $\begin{array}{l}\text { Lymph node metastasis, } \\
\text { n (\%) }\end{array}$ & Positive & $7(8.6)$ & $4(12.1)$ & 0.73 & $9(9.6)$ & $2(10)$ & 1.0 \\
\hline $\begin{array}{l}\text { (Only lesions removed } \\
\text { surgically) }\end{array}$ & Negative & 74 (91.4) & $29(87.9)$ & & $85(90.4)$ & $18(90)$ & \\
\hline
\end{tabular}

Horizontal rigidity-positive is defined as horizontal rigidity $\geq 4.5 \mathrm{~mm}$. Vertical rigidity-positive is defined as vertical rigidity $\geq 0.7 \mathrm{~mm}$ Continuous values are indicated as mean \pm SD (standard deviation). JNET: Japan narrow-band imaging expert team

well well differentiated adenocarcinoma, mod moderately differentiated adenocarcinoma, pap papillary adenocarcinoma, poor poorly differentiated

adenocarcinoma, sig signet-ring cell carcinoma, muc mucinous adenocarcinoma

Table 3 Comparison of the diagnostic ability for submucosal invasion depth $\geq 1.8 \mathrm{~mm}$ between horizontal and vertical rigidities under the barium enema examination profile view

\begin{tabular}{llll}
\hline $\mathbf{1 4 5}$ lesions & \multicolumn{2}{l}{ Vertical rigidity $(\geq \mathbf{0 . 7} \mathbf{~ m m})$} \\
\hline Horizontal rigidity $(\geq 4.5 \mathrm{~mm})$ & & Positive & Negative \\
& Positive & 87 & 1 \\
& Negative & 21 & 36 \\
$X 2$ & & 16.41 & \\
$P$ value & & 0.01 & \\
\hline
\end{tabular}

correlation between wall rigidity under the $\mathrm{BE}$ profile view and invasion depth in T1-CRC. Our results showed that horizontal and vertical rigidity are modest signs for the diagnosis of SM invasion depth in CRC. Although we were not able to quantify the pathologic findings in the present study, it can be presumed that the horizontal and vertical rigidity reflect the volume of fibrosis associated with cancer infiltration.

For the diagnosis of SM invasion depth $\geq 1 \mathrm{~mm}$ under $\mathrm{BE}$, Watari et al. [13] reported that the accuracy of radiographic findings, such as fold convergency, eccentric deformity on the profile view, deep central depression, irregularity in depression and tumor size $>20 \mathrm{~mm}$, was $85 \%$ in cases positive for at least one of those radiographic findings. Hisabe et al. [30] showed that the accuracy of the enface rigidity under $\mathrm{BE}$ for the diagnosis 
Table 4 Comparison of the incidence of colorectal cancers with submucosal invasion depth $\geq 1.8 \mathrm{~mm}$ between the combinations of horizontal and vertical rigidities under the barium enema examination profile view

\begin{tabular}{|c|c|c|c|c|c|}
\hline 145 lesions & & $\begin{array}{l}\text { Positive for horizontal and vertical } \\
\text { rigidity }(n=87)\end{array}$ & $\begin{array}{l}\text { Positive for either rigidity } \\
(n=22)\end{array}$ & $\begin{array}{l}\text { Negative for both } \\
\text { rigidities }(n=36)\end{array}$ & $\begin{array}{l}P \\
\text { value }\end{array}$ \\
\hline \multirow[t]{2}{*}{$\begin{array}{l}\text { Depth of submucosal } \\
\text { invasion, } \mathrm{n}(\%)\end{array}$} & $\begin{array}{l}<1.8 \\
\mathrm{~mm}\end{array}$ & 12 (13.8) & $12(54.5)$ & 29 (80.6) & 0.0001 \\
\hline & $\begin{array}{l}\geq 1.8 \\
\mathrm{~mm}\end{array}$ & $75(86.2)^{*^{+}}$ & $10(45.5)^{*}$ & $7(19.4)^{\dagger}$ & \\
\hline
\end{tabular}

Positive for horizontal rigidity is defined as horizontal rigidity $\geq 4.5 \mathrm{~mm}$. Positive for vertical rigidity is defined as vertical rigidity $\geq 0.7 \mathrm{~mm}$

${ }^{*} P=0.0006,{ }^{\dagger} P=0.0003$

of $\mathrm{SM}$ invasion $\geq 1 \mathrm{~mm}$ was $82 \%$ for the protruding type and $78.8 \%$ for the superficial type. Those prior studies evaluated the value of $\mathrm{BE}$ for the distinction of SM invasion depth $\geq 1 \mathrm{~mm}$ and $<1 \mathrm{~mm}$. Although $\mathrm{SM}$ invasion depth $\geq 1 \mathrm{~mm}$ is a pathologic risk factor for lymph node metastasis, it has been shown that the rate of lymph node metastasis was only $1-2 \%$ in T1-CRCs negative for the other risk factors, although the SM invasion depth was greater than $1 \mathrm{~mm}[9,31,32]$. Furthermore, Nakadoi et al. [5] showed that T1-CRCs with SM invasion depth $<1.8 \mathrm{~mm}$ without the other risk factors were completely free from lymph node metastasis. Based on this observation, we applied a cut-off value of $1.8 \mathrm{~mm}$ in this study. Consequently, our study showed that horizontal rigidity may be predictive of lympho-vascular invasion. However, it should also be noted that $17.5 \%$ of CRCs negative for horizontal rigidity actually had lymphovascular invasion. These results suggest that the rigidities under $\mathrm{BE}$ may be useful for the prediction of lympho-vascular invasion, but they should not be regarded as absolute markers.

Our results indicated that there was a statistically significant difference in the diagnostic value between horizontal rigidity and vertical rigidity. This observation suggests that each rigidity is independent of the other in the interpretation of $\mathrm{BE}$ findings. In addition, the prevalence of lympho-vascular invasion was different when lesions were classified by horizontal rigidity, and, furthermore, the rate of SM invasion depth $\geq 1.8 \mathrm{~mm}$ was statistically significantly different when lesions were classified into three groups according to the combination of horizontal and vertical rigidity. We thus believe that both rigidities should be carefully and independently assessed for the diagnosis of invasion depth when BE is to be applied to T1-CRC.

Studies of three-dimensional computed tomography air-contrast enema (CT enema) simulating BE have been reported [28, 29, 33-35]. Also, computer-aided diagnosis systems including artificial intelligence (AI) have been developed [36, 37]. Several studies have measured the wall rigidity under the profile view of the $\mathrm{CT}$ enema in CRC. In a previous study, vertical rigidity in a crosssectional multiplanar reconstruction image was found to have a sensitivity of $90.5 \%$ and a specificity of $100 \%$ for differentiating T1-CRC from high-grade dysplasia [29]. In other studies, a combination of the length of the deformity and the angle of the deformed outline correlated significantly with the invasion depth of CRCs, with an accuracy of $88.7 \%$ for the diagnosis of T1-CRC [28, 33, 38]. Thus, we can apply wall rigidity under BE to CT enema, and we may also be able to improve the diagnostic ability of AI-assisted CT enema with deep learning by understanding wall rigidity under $\mathrm{BE}$.

The present study has several limitations. First, because we studied T1-CRCs that were evaluated by BE, $\mathrm{M}-\mathrm{NBI}$, and MCE, we may have evaluated CRCs in which the diagnosis of invasion depth was extremely difficult. It thus seems possible that the subject lesions of our study may not have been representative of overall T1-CRCs. Second, because this was a retrospective study, we could not control for heterogeneity in the quality of $\mathrm{BE}$ and colonoscopic images. However, this limitation does not preclude the application of our findings in the clinical setting. Third and most significantly, the use of $\mathrm{BE}$ is decreasing. However, our findings appear significant when AI-assisted CT enema can be

Table 5 Comparison of diagnostic test results of horizontal and vertical rigidities under the barium enema examination profile view for predicting submucosal invasion depth $\geq 1.8 \mathrm{~mm}$

\begin{tabular}{|c|c|c|c|c|c|}
\hline & Sensitivity (\%) & Specificity (\%) & PPV (\%) & NPV (\%) & Accuracy (\%) \\
\hline Horizontal rigidity $\geq 4.5 \mathrm{~mm}$ & 82.6 & 77.4 & 86.4 & 71.9 & 80.7 \\
\hline Vertical rigidity $\geq 0.7 \mathrm{~mm}$ & 91.3 & 54.7 & 77.8 & 78.4 & 77.9 \\
\hline Horizontal rigidity $\geq 4.5 \mathrm{~mm}$ and vertical rigidity $\geq 0.7 \mathrm{~mm}$ & 81.5 & 77.4 & 86.2 & 70.1 & 80.0 \\
\hline
\end{tabular}

PPV positive predictive value, NPV negative predictive value 
applied for the assessment of wall rigidity. The cut-off value of $4.5 \mathrm{~mm}$ for horizontal rigidity in this study may be able to be applied to CT enema. In contrast, the limited vertical rigidity in this study may be not applicable to CT enema when the overall spatial resolution of CT is taken into consideration. Finally, we could not show data of inter-observer variation or a second independent validation cohort to validate most appropriate cut-off value for the rigidity, because the number of T1-CRCs in our retrospective cohort was small. It thus is necessary to validate our observations in a prospective cohort.

\section{Conclusions}

Our study revealed that the horizontal and vertical rigidities under a BE profile view were correlated with SM invasion depth. Using the cut-off values for predicting SM invasion depth $\geq 1.8 \mathrm{~mm}$, horizontal rigidity may be predictive of lympho-vascular invasion. These findings may be helpful for decision making in the treatment of T1CRCs.

\begin{abstract}
Abbreviations
ER: Endoscopic resection; ESD: Endoscopic submucosal dissection; EMR: Endoscopic mucosal resection; CRC: Colorectal cancer; T1 CRC: Submucosally invasive colorectal cancer; SM: Submucosal; JSCCR: The Japanese Society for Cancer of the Colon and Rectum; BE: Barium enema examination; M-NBI: Magnifying narrow-band imaging colonoscopy; MCE: Magnifying chromoendoscopy; JNET: Japan narrow-band imaging EXpert Team; SD: Standard deviation; ROC: Receiver-operating characteristic; AUC: Area under the curve; PPV: Positive predictive value; NPV: Negative predictive value; $C T$ enema: Computed tomography air-contrast enema; Al: Artificial intelligence; well: well-differentiated adenocarcinoma; mod: moderately differentiated adenocarcinoma; pap: papillary adenocarcinoma; poor: poorly differentiated adenocarcinoma; sig: signet-ring cell carcinoma; muc: mucinous adenocarcinoma
\end{abstract}

\section{Acknowledgements}

Not applicable.

\section{Authors' contributions}

KK designed the study and was involved in patient management, performed barium enema and endoscopic examinations, evaluated radiographic and endoscopic findings, and drafted the manuscript. TT helped to draft the manuscript. TN evaluated radiographic and endoscopic findings. ME, KK, ME and $\mathrm{YT}$ helped to draft the manuscript. MF reviewed the histologic specimens and was responsible for the pathologic diagnosis. SK helped to draft the manuscript. YO reviewed the histologic specimens and was responsible for the pathologic diagnosis. SY, KI, SF, YF, YM, JU, TM and TK helped to draft the manuscript. TS reviewed the histologic specimens and was responsible for the pathologic diagnosis. TM critically reviewed and revised the manuscript. All authors have read and approved the final version of the manuscript.

\section{Funding}

Not applicable.

\section{Availability of data and materials} Not applicable.

\section{Declarations}

\section{Ethics approval and consent to participate}

This study was approved by the Institutional Review Board, and informed consent was waived due to the retrospective nature of the study.
Consent for publication

Not applicable.

\section{Competing interests}

The authors declare that they have no competing interests.

\section{Author details}

${ }^{1}$ Department of Medicine and Clinical Science, Graduate School of Medical Sciences, Kyushu University, 3-1-1, Maidashi, Higashi-ku, Fukuoka 812-0054, Japan. ${ }^{2}$ Division of Gastroenterology, Department of Internal Medicine, Iwate Medical University, Yahaba 028-3695, Japan. ${ }^{3}$ Division of Gastroenterology, Department of Internal Medicine, Faculty of Medicine, Saga University, Saga 849-8501, Japan. ${ }^{4}$ Division of Gastroenterology, Matsuyama Red Cross Hospital, Matsuyama 790-8524, Japan. ${ }^{5}$ Department of Diagnostic Pathology, Iwate Medical University, Yahaba 790-8524, Japan. ${ }^{6}$ Department of Pathology, National Hospital Organization Kyushu Medical Center, Fukuoka 810-8563, Japan. ${ }^{7}$ Department of Anatomic Pathology, Graduate School of Medical Sciences, Kyushu University, Fukuoka 812-0054, Japan. ${ }^{8}$ Department of Pathology, Matsuyama Red Cross Hospital, Matsuyama 790-8524, Japan.

Received: 6 August 2021 Accepted: 24 November 2021

Published online: 07 December 2021

\section{References}

1. Fujiya M, Tanaka K, Dokoshi T, Tominaga M, Ueno N, Inaba Y, et al. Efficacy and adverse events of EMR and endoscopic submucosal dissection for the treatment of colon neoplasms: a meta-analysis of studies comparing EMR and endoscopic submucosal dissection. Gastrointest Endosc. 2015;81(3):58395. https://doi.org/10.1016/j.gie.2014.07.034.

2. Watanabe D, Toyonaga T, Ooi M, Yoshizaki T, Ohara Y, Tanaka S, et al. Clinical outcomes of deep invasive submucosal colorectal cancer after ESD. Surg Endosc. 2018;32(4):2123-30. https://doi.org/10.1007/s00464-017-5910-5.

3. Hashiguchi Y, Muro K, Saito Y, Ito Y, Ajioka Y, Hamaguchi T, et al. Japanese Society for Cancer of the Colon and Rectum (JSCCR) guidelines 2019 for the treatment of colorectal cancer. Int J Clin Oncol. 2020;25(1):1-42. https://doi. org/10.1007/s10147-019-01485-z.

4. Kaltenbach T, Anderson JC, Burke CA, Dominitz JA, Gupta S, Lieberman D, et al. Endoscopic removal of colorectal lesions-recommendations by the US multi-society task force on colorectal cancer. Gastroenterology. 2020;158(4): 1095-129. https://doi.org/10.1053/j.gastro.2019.12.018.

5. Nakadoi K, Tanaka S, Kanao H, Terasaki M, Takata S, Oka S, et al. Management of $\mathrm{T} 1$ colorectal carcinoma with special reference to criteria for curative endoscopic resection. J Gastroenterol Hepatol. 2012;27(6):105762. https://doi.org/10.1111/j.1440-1746.2011.07041.x.

6. Bosch SL, Teerenstra S, de Wilt JH, Cunningham C, Nagtegaal ID. Predicting lymph node metastasis in pT1 colorectal cancer: a systematic review of risk factors providing rationale for therapy decisions. Endoscopy. 2013;45(10): 827-34. https://doi.org/10.1055/s-0033-1344238.

7. Kawachi H, Eishi Y, Ueno H, Nemoto T, Fujimori T, Iwashita A, et al. A threetier classification system based on the depth of submucosal invasion and budding/sprouting can improve the treatment strategy for T1 colorectal cancer: a retrospective multicenter study. Mod Pathol. 2015;28(6):872-9. https://doi.org/10.1038/modpathol.2015.36.

8. Yasue C, Chino A, Takamatsu M, Namikawa K, Ide D, Saito S, et al. Pathological risk factors and predictive endoscopic factors for lymph node metastasis of $\mathrm{T} 1$ colorectal cancer: a single-center study of 846 lesions. J Gastroenterol. 2019; 54(8):708-17. https://doi.org/10.1007/s00535-019-01564-y.

9. Japanese Society for Cancer of the Colon and Rectum (ed.) Japanese classification of colorectal, appendiceal, and anal carcinoma. the 3rd English ed. J Anus Rectum Colon. 2019;3:175-95. https://doi.org/10.23922/jarc.2019018.

10. Park EY, Baek DH, Lee MW, Kim GH, Park DY, Song GA. Long-term outcomes of T1 colorectal Cancer after endoscopic resection. J Clin Med. 2020;9(8): 2451. https://doi.org/10.3390/jcm9082451.

11. Lee KL, Chiu NC, Su CW, Tseng HS, Lee RC, Liu CA, et al. Less barium enema, more colonoscopy: a 12-year nationwide population-based study in Taiwan. J Chin Med Assoc. 2019;82(4):312-7. https://doi.org/10.1097/JCMA. 0000000000000074.

12. Li YZ, Wu PH. Conventional radiological strategy of common gastrointestinal neoplasms. World J Radiol. 2015;7(1):7-16. https://doi.org/1 0.4329/wjr.v7.11.7. 
13. Watari J, Saitoh Y, Obara T, Fujiki T, Taniguchi M, Nomura M, et al. Early non-polypoid colorectal cancer: radiographic diagnosis of depth of invasion. Radiology. 1997;205(1):67-74. https://doi.org/10.1148/ra diology.205.1.9314964

14. Sano Y, Tanaka S, Kudo SE, Saito S, Matsuda T, Wada Y, et al. Narrow-band imaging (NBI) magnifying endoscopic classification of colorectal tumors proposed by the Japan NBI expert team. Dig Endosc. 2016;28(5):526-33. https://doi.org/10.1111/den.12644.

15. Kudo S, Tamura S, Nakajima T, Yamano H, Kusaka H, Watanabe H. Diagnosis of colorectal tumorous lesions by magnifying endoscopy. Gastrointest Endosc. 1996;44(1):8-14. https://doi.org/10.1016/s0016-5107(96)70222-5.

16. Tobaru T, Mitsuyama K, Tsuruta O, Kawano H, Sata M. Sub-classification of type $\mathrm{VI}$ pit patterns in colorectal tumors: relation to the depth of tumor invasion. Int J Oncol. 2008;33:503-8. https://doi.org/10.3892/ijo_00000033.

17. Sumimoto K, Tanaka S, Shigita K, Hirano D, Tamaru Y, Ninomiya Y, et al. Clinical impact and characteristics of the narrow-band imaging magnifying endoscopic classification of colorectal tumors proposed by the Japan NBI expert team. Gastrointest Endosc. 2017;85(4):816-21. https://doi.org/10.1016/ j.gie.2016.07.035

18. Komeda Y, Kashida H, Sakurai T, Asakuma Y, Tribonias G, Nagai T, et al. Magnifying narrow band imaging (NBI) for the diagnosis of localized colorectal lesions using the Japan NBI expert team (JNET) classification. Oncology. 2017;93(1):49-54. https://doi.org/10.1159/000481230.

19. Zhang JJ, Gu LY, Chen XY, Gao YJ, Ge ZZ, Li XB. Endoscopic diagnosis of invasion depth for early colorectal carcinomas: a prospective comparative study of narrow-band imaging, acetic acid, and crystal violet. Medicine (Baltim). 2015;94:e528. https://doi.org/10.1097/MD.0000000000000528.

20. Wada Y, Kashida H, Kudo SE, Misawa M, Ikehara N, Hamatani S. Diagnostic accuracy of pit pattern and vascular pattern analyses in colorectal lesions. Dig Endosc. 2010;22:192-9. https://doi.org/10.1111/j.1443-1661.2010.00983.x.

21. Participants in the Paris Workshop. The Paris endoscopic classification of superficial neoplastic lesions: esophagus, stomach, and colon. Gastrointest Endosc. 2003;58:S3-S43. https://doi.org/10.1016/s0016-5107(03)02159-x.

22. Matsumoto T, Esaki M, Hizawa K, Kurahara K, Hirakawa K, Yao T, et al. Accuracy of radiographic assessment for the diagnosis of invasion depth in small invasive colorectal cancer. Br J Radiol. 2003;76(909):611-6. https://doi. org/10.1259/bjr/63403347.

23. WHO classification of tumours editorial board. WHO classification of tumors: digestive system tumours. 5th ed. Lyon, France: International Agency for Research on Cancer; 2019.

24. Ueno H, Murphy J, Jass JR, Mochizuki H, Talbot IC. Tumour 'budding' as an index to estimate the potential of aggressiveness in rectal cancer. Histopathology. 2002;40(2):127-32. https://doi.org/10.1046/j.1365-2559.2002. 01324.x.

25. Ueno H, Mochizuki H, Hashiguchi Y, Shimazaki H, Aida S, Hase K, et al. Risk factors for an adverse outcome in early invasive colorectal carcinoma. Gastroenterology. 2004;127(2):385-94. https://doi.org/10.1053/j.gastro.2004 04.022.

26. Schober P, Boer C, Schwarte LA. Correlation coefficients: appropriate use and interpretation. Anesth Analg. 2018;126(5):1763-8. https://doi.org/1 0.1213/ANE.0000000000002864

27. Kitajima K, Fujimori T, Fujii S, Takeda J, Ohkura Y, Kawamata H, et al. Correlations between lymph node metastasis and depth of submucosal invasion in submucosal invasive colorectal carcinoma: a Japanese collaborative study. J Gastroenterol. 2004;39(6):534-43. https://doi.org/10.1 007/s00535-004-1339-4.

28. Kayashima Y, Kimura F, Inoue K, Honda Y, Nakanishi T, Ito K. Computed tomographic air-contrast enema imaging for presurgical examination of colon tumors: assessment with colon phantoms and in patients. Radiat Med. 2008;26(1):6-14. https://doi.org/10.1007/s11604-007-0185-8.

29. Miyasaka M, Tsurumaru D, Nishimuta Y, Asayama Y, Kawanami S, Oki E, et al. Diagnosis of early colorectal cancer invasion depth by quantitative evaluation of the basal indentation in CT colonography. Jpn J Radiol. 2016; 34(12):786-94. https://doi.org/10.1007/s11604-016-0586-7.

30. Hisabe T, Tanabe H, Aomi Y, Ishikawa S, Ishihara H, Karashima Y, et al. The usefulness of barium enema examination for the diagnosis of $\mathrm{T} 1 \mathrm{~b}$ colorectal cancer [in Japanese]. Stomach Intestine. 2014;49:990-1001.

31. Miyachi H, Kudo SE, Ichimasa K, Hisayuki T, Oikawa H, Matsudaira S, et al. Management of $\mathrm{T} 1$ colorectal cancers after endoscopic treatment based on the risk stratification of lymph node metastasis. J Gastroenterol Hepatol. 2016;31(6):1126-32. https://doi.org/10.1111/jgh.13257.
32. Kim B, Kim EH, Park SJ, Cheon JH, Kim TI, Kim WH, et al. The risk of lymph node metastasis makes it unsafe to expand the conventional indications for endoscopic treatment of T1 colorectal cancer: A retrospective study of 428 patients. Medicine (Baltimore). 2016;95:e4373. https://doi.org/10.1097/MD. 0000000000004373.

33. Nagata K, Endo S, Kudo SE, Kitanosono T. Kushihashi. CT air-contrast enema as a preoperative examination for colorectal cancer. Dig Surg. 2004;21(5-6): 352-8. https://doi.org/10.1159/000081543.

34. Utano K, Endo K, Togashi K, Sasaki J, Kawamura HJ, Horie H, et al. Preoperative $T$ staging of colorectal cancer by $C T$ colonography. Dis Colon Rectum. 2008;51(6):875-81. https://doi.org/10.1007/s10350-008-9261-0.

35. Hoshino N, Sakamoto T, Hida K, Sakai Y. Diagnostic accuracy of computed tomography colonography for tumor depth in colorectal cancer: a systematic review and meta-analysis. Surg Oncol. 2019;30:126-30. https:// doi.org/10.1016/j.suronc.2019.08.003.

36. Ren Y, Ma J, Xiong J, Lu L, Zhao J. High-performance CAD-CTC scheme using shape index, multiscale enhancement filters, and radiomic features. Trans Biomed Eng. 2017;64(8):1924-34. https://doi.org/10.1109/TBME.2016.2 631245.

37. Ziemlewicz TJ, Kim DH, Hinshaw JL, Lubner MG, Robbins JB, Pickhardt PJ. Computer-aided detection of colorectal polyps at CT colonography. Prospective clinical performance and third-party reimbursement. AJR Am J Roentgenol. 2017;208(6):1244-8. https://doi.org/10.2214/AJR.16.17499.

38. Sato K, Tanaka T, Sato J, Shibata E, Nagai Y, Murono K, et al. Usefulness of preoperative CT colonography for colon cancer. Asian J Surg. 2017;40(6): 438-43. https://doi.org/10.1016/j.asjsur.2016.04.002.

\section{Publisher's Note}

Springer Nature remains neutral with regard to jurisdictional claims in published maps and institutional affiliations.

Ready to submit your research? Choose BMC and benefit from:

- fast, convenient online submission

- thorough peer review by experienced researchers in your field

- rapid publication on acceptance

- support for research data, including large and complex data types

- gold Open Access which fosters wider collaboration and increased citations

- maximum visibility for your research: over $100 \mathrm{M}$ website views per year

At BMC, research is always in progress.

Learn more biomedcentral.com/submissions 